\title{
The development of absorptive capacity-based innovation in a construction SME
}

\author{
Rodney McAdam, Kristel Miller, Nora McMacken and John Davies
}

\begin{abstract}
Traditionally, construction has been a transaction-oriented industry. However, it is changing from the design-bid-build process into a business based on innovation capability and performance management, in which contracts are awarded on the basis of factors such as knowledge, intellectual capital and skills. This change presents a challenge to construction-sector SMEs with scarce resources, which must find ways to innovate based on those attributes to ensure their future competitiveness. This paper explores how dynamic capability, using an absorptive capacity framework in response to these challenges, has been developed in a construction-based SME. The paper also contributes to the literature on absorptive capacity and innovation by showing how the construct can be operationalized within an organization. The company studied formed a Knowledge Transfer Partnership using action research over a two-year period with a local university. The aim was to increase its absorptive capacity and hence its ability to meet the changing market challenges. The findings show that absorptive capacity can be operationalized into a change management approach for improving capability-based competitiveness. Moreover, it is important for absorptive capacity constructs and language to be contextualized within a given organizational setting (as in the case of the construction-based SME in the present study).
\end{abstract}

Keywords: absorptive capacity; construction; SMEs; Knowledge Transfer Partnership

Rodney McAdam is Head of the Department of Marketing, Entrepreneurship and Strategy, University of Ulster, Jordanstown Campus, Shore Road, Newtownabbey, County Antrim, Northern Ireland BT37 0QB, UK. E-mail: r.mcadam@ulster.ac.uk. Kristel Miller and Nora McMacken are also in the Department of Marketing, Entrepreneurship and Strategy at the University of Ulster. John Davies is with the Salford Business School, University of Salford, UK.

Traditionally, the UK construction industry has been transaction-oriented, with work being obtained by successfully bidding for and completing contracts (Briscoe and Dainty, 2005). However, the construction industry is moving away from this traditional designbid-build process to a new innovation capability and performance-based approach in which contracts are awarded on factors such as knowledge, intellectual capital and skill (Khalfin et al, 2007; Reason and Bradbury, 2001). As the construction industry is an increasingly competitive environment, both the firm and employees of the firm must have the dynamic capability to learn quickly, integrate new knowledge and transform and implement this new knowledge within the business processes, procedures and routines (Reason and Bradbury, 2001; Daghfous, 2004). This approach will 
increase the overall innovation and competitiveness of the company in construction markets, where a demonstration of innovative organizational capability is now required (Mathews et al, 2000).

The dynamic capability of a firm to recognize the value of new external information, assimilate it and apply it is critical to sustaining competitive advantage and to innovating (Cohen and Levinthal, 1990), especially in rapidly changing market conditions such as the construction market for public procurement. Absorptive capacity (ACAP) is what enables an organization effectively to acquire, use, transform and implement information vital for the growth of a knowledge-sharing culture and to the firm's operations (Cohen and Levinthal, 1990). ACAP ‘...enhances a firm's ability to gain and sustain a competitive advantage' (Zahra and George, 2002, p 185). It also enables the firm to adapt to the changing market conditions. However, Jones (2006), along with Zahra and George (2002), states that the study of ACAP in organizations is limited by a lack of definition at an operational level within these organizations. Easterby-Smith et al (2008) conclude that there is a need for further studies in different types of organizations to develop further understanding of the construct and adopt a process approach to ACAP. Hence, the main aim of this paper is to explore how dynamic capability using an absorptive capacity framework in response to these challenges has been developed within a construction-based SME (which specializes in public contracts).

\section{Review of construction sector challenges for SMEs}

The construction industry was traditionally an instantaneous, transaction-oriented business. For decades, the inflexible structure of 'third party' contracts inhibited the construction industry's creative response to the needs of its clientele (Burnes and Coram, 1999). The Egan report (1998) and the ensuing Rethinking Construction Initiative show that the UK construction industry is an increasingly competitive environment and is moving away from the traditional design-bid-build process to a new organizational innovation capability and performance-based approach in which jobs are awarded based on skill (Mathews et al, 2000). Thus, there is a challenge for construction firms to find ways to improve these attributes in a systematic and sustained manner to ensure future competitiveness. According to Hari et al (2005, p 533), 'construction organisations have been managing knowledge informally for years, but the challenges facing today's industry mean that most organisations now need a more structured, coherent approach to knowledge management'. A key characteristic of the UK construction industry is its fragmented structure, with a large number $(99 \%$ of the total - Hari et al, 2005) of competing small and medium-sized enterprises (SMEs). According to Reason and Bradbury (2001), the SME sector is critically important to the overall efficiency of the UK construction industry, which takes up a large proportion of the economy. In 2005, the industry employed in excess of 1.5 million people, contributing approximately $8 \%$ of total gross domestic product - GDP (Hari et al, 2005). The innovation capability challenge for constructionbased SMEs is increased by their inherent lack of resources and skills (Hari et al, 2005).

Between 2000 and 2007, the construction industry in Northern Ireland (NI) was growing steadily due to increases in economic growth. In 2007, the Construction Industry Training Board (CITB) forecasted that employment in construction would grow by $13 \%$ in Northern Ireland over five years, needing another 2,620 new employees each year to meet the demand. However, following the recent economic downturn, the Northern Ireland construction workforce has plummeted (Millar, 2008). There was a commensurate increase in the number of construction workers (in excess of $300 \%$ ) claiming benefits from January 2008 to January 2010 (CEFNI.com).

In addition to the job losses, there has been a shortage of apprenticeship places as a conduit towards long-term capacity building within SMEs (Taylor, 2008, p 3).

\section{Developing an absorptive capacity perspective and research questions}

As the construction industry is extremely volatile and varied, it is essential that construction-based companies remain competitive by having the dynamic capability to respond to such challenges (Cheng and Li, 2004; Mathews et al, 2000). They must have the dynamic capability to learn quickly, integrate new knowledge and transform and implement this new knowledge in their business routines and processes to increase effectiveness and competitiveness (Jones, 2006; Daghfous, 2004).

Absorptive capacity (ACAP) has been defined as a dynamic capability that enables a firm effectively to acquire and utilize external and internal knowledge, which affects the firm's ability to innovate and adapt to its changing environment and hence to increase its competitiveness (Cohen and Levinthal, 1990; Zahra and George, 2002; Lane et al, 2006). Dynamic capability can be defined as 'the firm's ability to integrate, build and reconfigure internal and external competences to address rapidly changing environments' (Teece et al, 1997, p 509). ACAP can be described as a dynamic capability that is based on 'the creation and utilisation of knowledge that contributes to improved competitive 


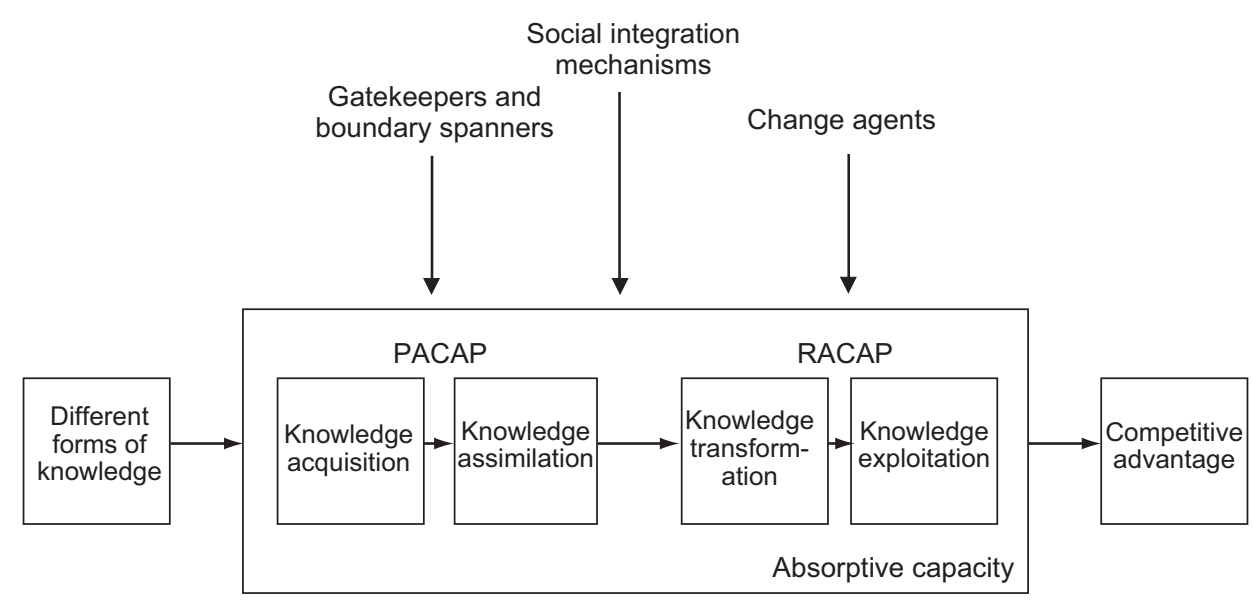

Figure 1. Absorptive capacity framework.

Source: Adapted from Zahra and George, 2002 and Jones, 2006.

advantage' (Jones, 2006, p 357). Jones (2001, 2006) describes absorptive capacity as the ability to learn and solve problems where the status quo and path dependencies are challenged, as is the situation in the construction market. Zahra and George (2002), in building upon Cohen and Levinthal's (1990) research, show the importance of ACAP in terms of achieving strategic and competitive advantage for the firm, in that ACAP '...enhances a firm's ability to gain and sustain a competitive advantage' (Zahra and George, 2002, p 188).

In modelling ACAP using a process view (similar to that of Easterby-Smith et al, 2008), four dimensions have been identified - as shown in Zahra and George's (2002) model (Figure 1). Also shown are activation triggers (that is, external - the change in the construction market's requirements; and internal - the organization forming a partnership to address the challenge at all levels), socialization mechanisms to incorporate and use new knowledge, gatekeepers who hold key roles in knowledge filtering and transfer, and boundary spanners who transcend organizational silos and help spread knowledge to all areas and levels of the organization. Each of the four dimensions has several key influencing factors (Zahra and George, 2002; Daghfous, 2004):

(1) Acquisition is how a firm identifies and acquires knowledge that is generated externally (Zahra and George, 2002), in which the key influencing factors are: prior internal knowledge, prior external knowledge, prior investments, human resources and communication (Zahra and George, 2002).

(2) Assimilation is how the firm can absorb, understand, analyse, process and interpret this new external knowledge. Key influencing factors are the level of education, diversity of backgrounds, organizational structure, internal communication and human resources (Zahra and George, 2002; Daghfous, 2004).

(3) Transformation is how the firm develops procedures to merge the new knowledge with the knowledge that already exists in the company. Key influencing factors are individual absorptive capacity, level of education, diversity of backgrounds, organizational structure, organizational culture, internal communication and human resources (Zahra and George, 2002; Daghfous, 2004).

(4) Exploitation is how the firm applies this newly developed information to achieve the organization's objectives (Lane and Lubatkin, 1998) with key influencing factors including human resources, individual absorptive capacity, organizational structure, bureaucracy and responsiveness (Zahra and George, 2002).

The absorptive capacity of an organization depends upon the absorptive capacity of the individuals and groups within that organization (Lane et al, 2006; Jones, 2006; Cohen and Levinthal, 1990). Jones (2006) explores the conceptualization of these organizational levels and boundaries by applying an 'agentization' approach. The accumulation and diversity of prior knowledge from individuals or agents at different levels, often neglected in relation to structural issues in ACAP studies (Jones, 2006), improves the ability of a firm to acquire and accumulate new knowledge. According to Linsu (2004), prior knowledge has a positive effect on absorptive capacity because it helps acknowledge the value of new information, assimilate it and apply it. Daghfous (2004) states that the level of education influences an individual's ACAP. Employees with higher 
levels of education in a field are perceived as better at absorbing new knowledge in a particular field. Investments in employee training develop the individual's absorptive capacity in the acquisition of new skills as well as the diversity of their knowledge base (Cohen and Levinthal, 1990), leading to some organizations 'buying in' ACAP by hiring new employees and forming alliances (Jones, 2006; Easterby-Smith et al, 2008).

Diversity of backgrounds and knowledge creates more opportunity for the new knowledge to be absorbed in the company by ensuring that multiple perspectives are applied and valued. Gatekeepers (Figure 1) are actors that serve as intermediaries between the company and the external knowledge environment, or between subunits within the organization (Daghfous, 2004), and hence are an influencing factor in ACAP as part of outward-looking absorptive capacity.

An organization's absorptive capacity is not simply the sum of the individuals' capabilities. It is also affected by other organizational factors (Cohen and Levinthal, 1990). The combination of systems capabilities (the company's formalized policies and procedures), coordination capabilities (the relationships between employees) and socialization capabilities (firm's shared ideology) determines how well the company can integrate the individual or agent's absorption capabilities (Linsu, 2004). Communication between the firm and the external knowledge environment or subunits and the development of formal and informal networks determine the strength of the absorptive capacity within the firm (Cohen and Levinthal, 1990). Inward-looking absorptive capacity is the interaction within the subunits. Both inward-looking and outward-looking absorptive capabilities are needed for companies to remain effective (Cohen and Levinthal, 1990). Inward, outward and subunit involvement imply the existence of boundaries that can limit ACAP at all levels. There is a need to a move beyond generic ACAP descriptors and generic structural applications (Jones, 2006) with the development of context-specific applications (Veugelers, 1997; Todorova and Durisin, 2007; Easterby-Smith et al, 2008), all of which leads to the first research question, consistent with the aim of the paper:

$R Q 1$ : How can absorptive capacity theory be applied to a construction-sector SME using appropriate tools and techniques to operationalize the construct across each of its four dimensions?

In this context, the term 'operationalize' refers to linking the theoretical ACAP framework to practical outworking within the organization's activities.

Although absorptive capacity is a broad framework within which to interpret market challenges in terms of the need to acquire, assimilate, transform and exploit knowledge effectively in support of addressing market challenges (Lane et al, 2006), there is a need to contextualize the framework for a given sector and organization (Todorova and Durisin, 2007), namely a construction-sector SME in the current context, leading to the second research question, which is developed from RQ1:

RQ2: What approaches can be adopted to contextualize absorptive capacity in a constructionsector SME environment, leading to improved approaches for dynamic capability to address market challenges?

Responses to this research question will be organizationspecific, but will also show the need for contextualization rather than applying generic approaches.

Zahra and George (2002) developed the constructs of potential absorptive capacity (PACAP: that is, acquisition and assimilation dimensions) and realized absorptive capacity (RACAP: that is, transformation and exploitation dimensions), as shown in Figure 1, to emphasize the need to utilize and apply knowledge effectively as part of a process (Easterby-Smith et al, 2008). These constructs present a commercialization or market challenge to organizations, as shown by Lane $e t$ al (2006) in attempting to develop absorptive capacity, leading to the third research question, which seeks to progress beyond PACAP:

RQ3: How can an SME use absorptive capacity constructs to increase RACAP and hence competitiveness in the rapidly changing construction-sector market?

\section{Research methodology}

The research philosophy, approach, methods and analysis are outlined based on Saunders et al's (2007) onion-layered approach to research and consistent with the style of the research questions suggested by Yin (2003). First, an interpretivist research philosophy was chosen - that of Saunders et al (2007, p 107), who see interpretivist philosophy as 'highly appropriate in the case of business and management research'. Moreover, an interpretivist research philosophy is suited to research that is focused on the understanding of people, their roles, perceptions and capabilities.

Second, an inductive research approach was selected, as this is concerned with building understanding from the context in which the events are taking place, and uses the flexible structure of qualitative data sources when the researcher can be part of the research process 
and when longitudinal data can be obtained - over a two-year period in the current study (Saunders et al, 2007; Jones and Craven, 2001). Easterby-Smith et al (2008) used a qualitative longitudinal approach to ACAP research, suggesting that it was suited to the stage of development of the construct.

Third, the research methods, consistent with the nature of the two-year Knowledge Transfer Partnership (KTP) programme, included action research, participant observation, semi-structured interviews and focus groups. Reason and Bradbury (2001, p 1) state that 'action research is a participatory, demographic process concerned with developing practical knowing in the pursuit of worthwhile human purposes, grounded in a participatory worldview'. Hussey and Hussey (1997, p 65) suggest that 'the main aim of action research is to enter into a situation, attempt to bring about change and to monitor the results'. The role of the KTP associate within the firm (DComp) was as a researcher and an employee, enabling a participant observer approach to be adopted in support of action research, resulting in first-hand experience of the situation. In order to gather information from the action research, repeat semi-structured interviews $(n=30)$ were carried out with management team members and a cross section of staff within DComp (that is, across all functions) in a planned manner over the 24-month period of the KTP programme. Focus groups $(n=24)$ in the form of facilitated management meetings were held with the associate each month, when the main agenda items reflected the aim and research questions stated earlier. Those involved included the Managing Director and management staff (from each of the key subunits within the company) of the KTP partner organization, along with the KTP associate as facilitator of the discussions. Further focus groups were held with a cross section of staff to ensure that perceptions from all areas and levels within the organization were represented and discussed. The secondary data sources included company documents and government publications relating to the construction sector.

Fourth, the method of analysis involved developing interpretive tables for each of the ACAP dimensions and influencing factors and then interpreting organizational improvements and contributions (determined from the data sources) for each of these elements over the twoyear period. The KTP associate's participant observer role enabled a relationship of trust and mutual exchange to be established (Remenyi et al, 1999). This developmental approach enabled the researchers to obtain reflective practitioner inputs, as suggested by Yin (2003).

\section{Results and discussion}

Given the qualitative nature of the findings, the results and discussion sections are combined, as suggested by Remenyi et al (1999).

\section{Knowledge Transfer Partnerships and the case SME}

The KTP scheme, originally known as the Teaching Company Scheme (TCS), was established by the Department of Trade and Industry (DTI) in the UK to improve the competitiveness of organizations by supporting links between the state, industry and knowledge base partners - mainly universities (Freeman and Soete, 1997; Jones and Craven, 2001). It is based on two-year partnerships between a knowledge base partner and companies who require the development of specialist skills and knowledge in a particular area.

The KTP firm (DComp) was a construction-sector SME. The Managing Director (MD) had understood the changing construction sector landscape and realized that the company lacked the in-house learning capability to adapt to, and deal with, emergent and future market challenges, especially with regard to dynamic capacity development at all levels, as suggested by Cheng and Li (2004) and Mathews et al (2000). The KTP programme's aim was to increase the absorptive capacity (ACAP) of the case organization and hence its effectiveness and competitiveness in addressing the competitiveness challenges of the changing construction-sector market. The organization was a family-run SME construction business that focused on being the principal contractor on major government building contracts, with an extensive client base that included councils, other public authorities, universities, colleges and schools. The company had 66 direct or full-time employees, a number of contingent project-based selfemployed staff, plus unskilled labour. The emphasis on public sector clients, such as councils, schools and universities, led to most of the work being secured through the tender screening process, which now involves an evaluation of organizational capability (Davis, 2008). Hence the company constantly had to look for ways to improve capability and performance so as to remain competitive.

\section{Operationalizing the development of ACAP}

In relation to RQ1, initial attempts by the key agents or KTP team (two academic researchers and a supervisor, KTP associate, two organizational supervisors - manager and senior manager, and the Managing Director) to apply the ACAP framework in an operational manner to drive change proved to be problematic. It was seen as being theoretical and as a summative and assessmentbased approach, rather than as a dynamic capability to 
be purposively driven and developed within the organization (Todorova and Durisin, 2007; Jones, 2006). To address this challenge, a series of learning-based tools and techniques, each of which contributed to some aspect of increasing individual, team and organizational ACAP, were adapted and trialled within the organization. This approach enabled ACAP to be operationalized, whereby specific operational steps could be implemented to increase and develop ACAP in the individuals and groups within the organization in a cumulative manner, as suggested by Linsu's (2004) study of the Hyundai Motor Company. Moreover, the approaches helped in translating practice-based (or pragmatic - Easterby-Smith et al, 2008) knowledge across external and internal boundaries within the organization.

Two of these tools, namely the balanced scorecard (Assiri et al, 2006) and the Investors in People (IiP) standard (Taylor and McAdam, 2003), related to ACAP being identified as a dynamic capability. The balanced scorecard, and the learning process whereby the balanced scorecard was developed, were used to identify and pursue a number of initiatives at different organizational levels or boundaries to improve processes, procedures and learning and growth routines, with commensurate development of performance measures, which led to improved dynamic capability or absorptive capacity of DComp in a similar manner to that suggested by Assiri et al (2006). Similarly, the adaptation of the IiP model and its learning-based implementation process enabled and structured the development of dynamic learning capabilities that included human resources, training and education, $\mathrm{R} \& \mathrm{D}$, communication and organizational culture and structure, and encouraged employees to act as both sources and conduits for knowledge across boundaries (in the pragmatic sense Easterby-Smith et al, 2008).

The balanced scorecard and Investors in People were used in an integrated manner to operationalize absorptive capacity. Figure 2 shows that, for each of the four dimensions of ACAP, there was an initial evaluation followed by an iterative process using the action learning methodology suggested by Jones (2006), which involved the KTP team applying the balanced scorecard

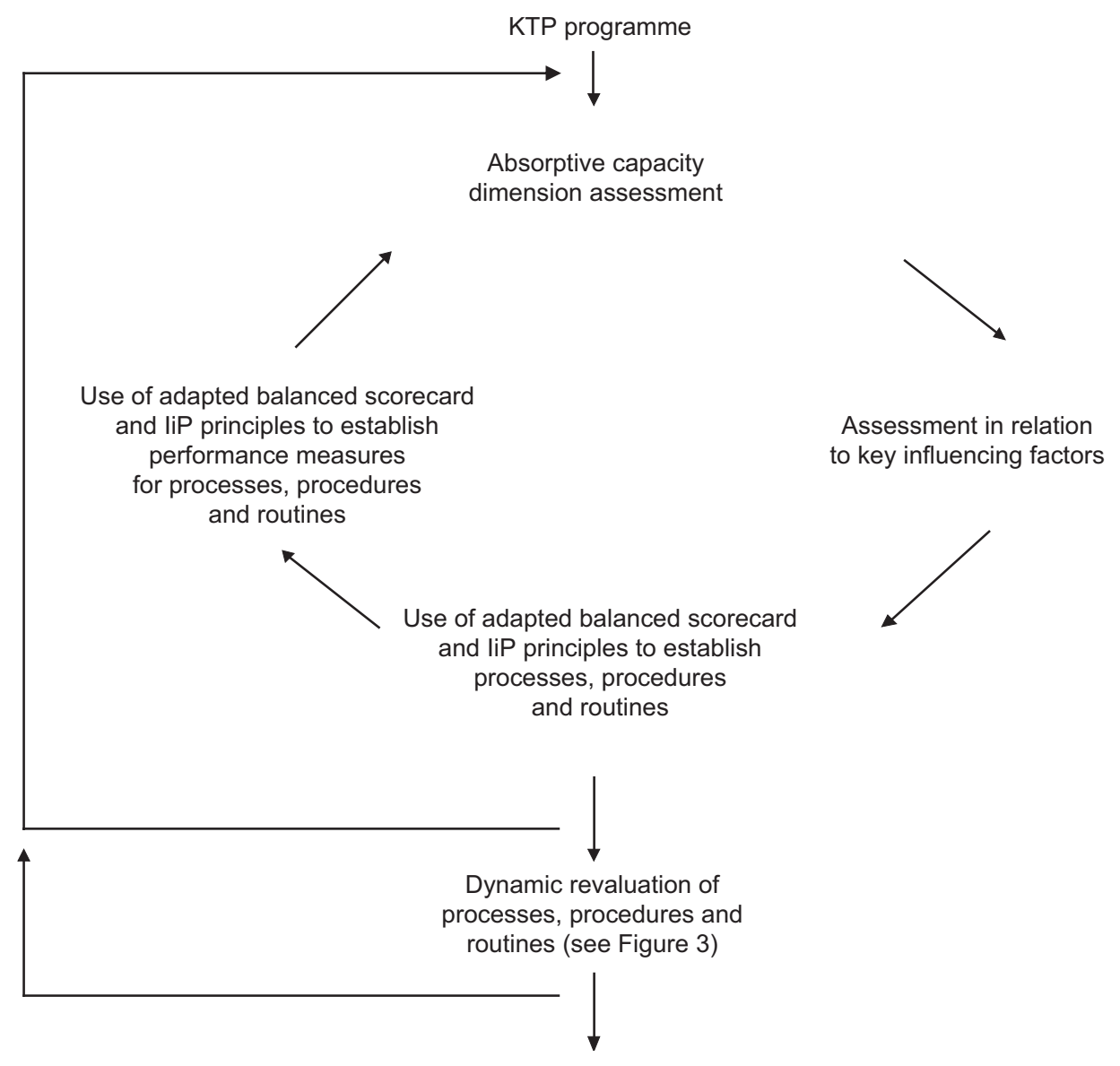

Figure 2. Operational learning loop for ACAP-based improvement. 


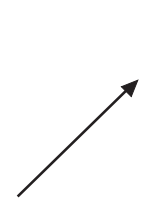

What assumptions are being made about the market, people, technology,

performance measurement or other pertinent factors?

\footnotetext{
Compare external approaches and adapt changes to procedures, processes and routines using this external knowledge
}

What are the implications in terms of changing processes, procedures or routines?
Are these assumptions still viable? If not, what new assumptions need to be added?
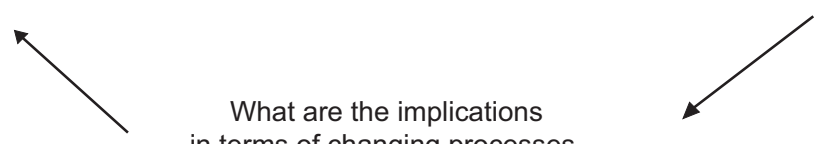

Figure 3. Dynamic learning loop for ACAP-based improvement.

and IiP learning processes to increase ACAP levels for each of the influencing factors of the respective ACAP dimension.

This action led to an evaluation for each of the influencing factors and ultimately a re-evaluation of the overall ACAP dimension. This learning loop was used by the action research team to increase and evaluate ACAP in relation to all four dimensions (Figure 1) and in relation to each of the influencing factors for each ACAP dimension and also to reflect on the overall process.

However, while initial trialling of this approach (Figure 2) led to new or improved routines beyond the status quo for each of the ACAP dimensions, there was a lack of inbuilt learning-to-learn elements within the routines, which meant that a new status quo or path dependency was quickly established (Lane et al, 2006), prompting the establishment of new core rigidities (Leonard-Barton, 2002). Thus, through the action learning methodology, a corollary 'learning-to-learn' routine was developed (Figures 2 and 3 ) to enable the firm to 'break out of existing path dependencies' (Jones, 2006; Cohen and Levinthal, 1990).

Figure 3 shows that this learning loop ensures that the underlying assumptions of the market and environment are continually questioned in relation to change actions (in a similar manner to that of double-loop learning) consistent with Burgoyne (1990, p 23, quoted by Jones, 2006), who states that the importance of 'learning, changing, adapting, forecasting, anticipating and creating change' within learning routines is operationalized, which in turn ensures that the shape of the operational process, procedure or routine is continually changed in line with market and organizational requirements. This approach required that all internal agents involved had to have a knowledge of changing external markets, which was aided by the translation processes within the balanced scorecard. The establish- ment of this 'routine for developing a routine', as shown in Figure 3, and as part of Figure 2, enabled the KTP team, plus the employees involved in each respective routine, to operationalize the development of new or improved processes, procedures and routines across the organization to contribute to all four dimensions of ACAP in helping to make a contribution towards addressing RQ1.

\section{Contextualizing and developing absorptive capacity with the case $\mathrm{SME}$}

The operationalizing process for ACAP within DComp, as shown in Figures 2 and 3, required that each of the four dimensions of ACAP and the associated influencing factors should be contextualized in terms of resultant organizational improvements in seeking to address RQ2. Tables 1-3 have been developed to summarize the ACAP improvements within DComp for the acquisition, assimilation and transformation dimensions of ACAP. The fourth dimension, namely exploitation, is illustrated later through a study of a specific process improvement.

\section{Acquisition}

Prior internal knowledge. According to Zahra and George (2002, p 191), 'the breadth and depth of knowledge exposure positively influence a firm's propensity to explore new and related knowledge'. The project nature of the construction industry is essentially a 'learning by doing' process. DComp goes through the iterative process of working - learning - building on a succession of projects. The acquisition of knowledge and experience of individuals within DComp is relatively high due to the strong skills and experience base, in which employee retention and training levels are high (Zahra and George, 2002). 
Table 1. Acquisition dimension: ACAP influencing factors and improvements.

\section{ACAP influencing Subfactor factor \\ (where appropriate)}

Prior internal

knowledge

Learning by doing

\section{Contextualization and improvements}

Experience. DComp has applied its experience of many distinct project types including education, commercial office buildings, healthcare, housing, sports, heritage and conservation works.

People. DComp employees are well qualified and have considerable experience, which is leveraged within its business processes.

Past experience Environmental scanning. As the construction industry is continuously changing, DComp scans the environment for innovative products and processes, which make a significant contribution to the whole life-cycle cost of a proposed project.

Interactions with customers. Constantly interacting with clients to obtain feedback and to improve quality projects on time and to budget.

Alliances with other firms. Establishment of joint improvement teams with clients to develop more market-facing activities.

Prior external knowledge

Gatekeepers; position in knowledge networks; relationships in knowledge networks

Prior investments Research and development

Investment in individual ACAP

Human resources Motivate continuous learning

Cross-functional communication
Communication among departments
The key agents use their influence and networks to promote the organization. Managing Director - Associate of the Chartered Institute of Building, Regional Economic Development Group, personal contacts, accountants, solicitor, planners, surveyors, architects, Construction Employers Federation. KTP associate - fellow KTP associates network and training courses. Access to university's knowledge and expertise.

Investment in ISO 9001:2000, ISO 14000, ISO 18000 Quality, Environmental and Safety Standards has led to improved practices and capability in procurement R\&D using a previous KTP.

Training and development plans for all staff in requisite skills have led to multiskilling and improved effectiveness of the workforce.

Continual improvement of the workforce through provision of adequate training to improve competence and through Investors in People and the balanced scorecard with specified improvement measures and targets.

Deployment of project management software linking all staff and an open-plan office for engineers to encourage communication among the different departments. Multi-level teams devolving the balanced scorecard.
The quarterly local management committee (LMC) meetings represented a key learning mechanism for absorbing new knowledge into the organization and reflecting on progress and problems that had proved useful for discussing new management ideas associated with the KTP project (Jones and Craven, 2001). These meetings, along with those of the management team, subunit balanced scorecard teams and Kaizen crossfunctional improvement teams, became key forums for assessing the effectiveness of acquiring new knowledge within DComp.

Prior external knowledge. The ACAP of DComp was also affected by the ability to form networks and relationships with stakeholders (Zahra and George, 2002) and to leverage these networks in key business processes (for example, the bidding process), which would ultimately contribute to increased competitiveness. DComp established relationships with public sector clients at multiple levels within the company (for example, engineers with the corresponding engineers, and managers with the corresponding managers). The networks utilized were both formal (for example, professional bodies, institutes of building and surveying) and informal (contacts within current and past alliances, local knowledge of the management team), which impacted positively on the acquisition of new knowledge (Daghfous, 2004).

Acquisition of new information was also influenced by the ability of DComp to respond to environmental cues. The factors that drive DComp include market opportunities and needs. As the construction industry is continuously changing, DComp needed to develop routines to scan the environment constantly for innovative products and processes that made a significant contribution to the whole life-cycle cost of a project and helped gain competitive advantage. Methods of scanning that were developed from the KTP project included benchmarking comparisons, analysis of markets and government spending trends. Engineers, acting as gatekeepers for each of the organizational subunits and their boundaries (Jones, 2006), have also been trained to look for new building materials and processes to reduce costs and improve environmental performance (for example, use of recyclable and heat-retaining materials).

Prior investments. DComp has increased investment in individual ACAP. Regular training courses have been provided to leverage and maximize its talents, skills and abilities, allowing it to achieve and maintain satisfactory 
Table 2. Assimilation dimension: ACAP influencing factors and improvements.

$\begin{array}{ll}\text { ACAP influencing } & \begin{array}{l}\text { Subfactor (where Contextualization and improvements } \\ \text { appropriate) }\end{array}\end{array}$

Levels of education

DComp employs staff with a high level of education and enables them to apply their learning to encourage the absorption of new knowledge in key areas including: accounts; quantity surveying; health and safety management; buying; management; skilled and semi-skilled trades; and administration.

Diversity of backgrounds

The diversity of backgrounds is used to increase the possibility that new knowledge will be related to knowledge already within DComp. There is a variety of perspectives from which to process acquired knowledge, such as new associations and linkages.

Human resources

There is now planned continual improvement of the workforce through provision of training and development to improve capability across all areas, and at all levels, of the company. Training is planned, managed and monitored through a coordinated Skills Development Programme produced with the assistance of the Construction Industry Training Board (CITB) and the local government funding agency, consistent with liP procedures.

Cross-functional communication The development and devolving of the balanced scorecard and liP approaches have led to improved communications in assimilating knowledge with a wider range of inputs in decision making. However communication could improve among departments, by employing a knowledge-sharing approach.

Organizational structure The structure is flat and flexible, giving employees a level of empowerment in accepting new knowledge into their routines and practices across the organization as a whole.

performance levels, as measured using an adaptation of the balanced scorecard (for example, project management surveys, quality, safety and environmental issues). This approach has helped in attracting and retaining a knowledgeable and skilled workforce, as suggested by Assiri et al (2006).

Cohen and Levinthal (1990) state that the ACAP of an organization is influenced by its investment in $R \& D$, and the higher the $R \& D$, the higher the absorptive capacity leading to improved capability to acquire new knowledge. The company has made significant investment in increasing its capability by obtaining ISO 9001:2000, ISO 14000 and ISO 18000 accreditations, which help in improving the internal effectiveness of the organization and in enhancing its market reputation, as shown by Mathews et al (2000).

Human resources. Human resource management (HRM) on the project sites depends on project managers and supervisors (traditionally called 'foremen') to implement the required processes and procedures (Briscoe and Dainty, 2005). However, the educational, contractual and procurement practices of the construction industry encourage management to adopt a job-centred culture (Loosemore et al, 2003) as opposed to dynamic capability development, which does not fit with the changing environment in which they operate.

Cross-functional communication. Daghfous (2004, p 24) states that: 'an organisational structure allowing the maximum amount of communication between various departments improves a firm's Absorptive Capacity'. Due to the widespread and varied locations of the building contracts undertaken by DComp, there was a lack of effective communication between the knowledge-producing and knowledge-using sites, similar to that found by Davenport and Prusak (1998). DComp's structure, however, is flat and flexible - which has enabled rapid communication in times of crisis (for example, preparation for impending deadlines; project completions to meet customer deadlines). The KTP programme has led to the top-down managerial style adopted by DComp being modified by devolving balanced scorecards to team level and improving the capability of managers in all areas of the company. The development of cross-functional routines (Figures 2 and 3) helped to increase the permeability of subunit boundaries, as suggested by Easterby-Smith et al (2008).

\section{Assimilation}

\section{Level of education and diversity of backgrounds.}

According to Daghfous (2004), level of education affects the assimilation of knowledge that has been acquired by an organization. There were personnel with differing levels of education throughout the company, with a diversity of backgrounds (for example, technical specialists such as quantity surveyors and buyers), who were regularly involved to improve the absorption of new knowledge through critique and consensus. This application of diversity enabled new knowledge to be related to knowledge already existing within the firm, resulting in improvements and innovations (Daghfous, 2004). ACAP levels held within DComp are dependent on the individuals within the firm (Daghfous, 2004). The company now encourages part-time study and offers specific training for individuals at all levels. Applying 
Table 3. Transformation dimension: ACAP influencing factors and improvements.

\begin{tabular}{|c|c|c|}
\hline $\begin{array}{l}\text { ACAP influencing } \\
\text { factor }\end{array}$ & $\begin{array}{l}\text { Subfactor } \\
\text { (where appropriate) }\end{array}$ & Contextualization and improvements \\
\hline \multirow[t]{2}{*}{$\begin{array}{l}\text { Individual } \\
\text { absorptive } \\
\text { capacity }\end{array}$} & Systems capabilities & $\begin{array}{l}\text { Formalized and interlinked policies, procedures and routines for health and safety, } \\
\text { quality, environmental and human resource management are used by teams to meet } \\
\text { client requirements (including industry regulators). }\end{array}$ \\
\hline & $\begin{array}{l}\text { Coordination } \\
\text { capabilities }\end{array}$ & $\begin{array}{l}\text { Relationship protocols were established between members in groups and with clients, } \\
\text { and were used to provide opportunities and to help employees reach their potential by } \\
\text { linking and transforming knowledge. }\end{array}$ \\
\hline \multicolumn{2}{|l|}{ Level of education } & $\begin{array}{l}\text { DComp employees were encouraged (via the balanced scorecard and liP) to use and } \\
\text { leverage their relatively high levels of education in key areas to improve the effectiveness } \\
\text { of routines for transforming knowledge (for example, improved client-facing procurement, } \\
\text { surveying, costing and project management routines). }\end{array}$ \\
\hline \multicolumn{2}{|l|}{$\begin{array}{l}\text { Internal } \\
\text { communication }\end{array}$} & $\begin{array}{l}\text { Improved communication of new procedures, routines and practices led to the effective } \\
\text { development of client-driven performance measurement in all areas and at all levels of } \\
\text { the company using the balanced scorecard and liP. }\end{array}$ \\
\hline \multicolumn{2}{|l|}{$\begin{array}{l}\text { Organizational } \\
\text { structure }\end{array}$} & $\begin{array}{l}\text { Informal networks and cross-functional teams were used by employees to develop new } \\
\text { procedures and routines to meet client needs. }\end{array}$ \\
\hline \multicolumn{2}{|l|}{ Organizational culture } & $\begin{array}{l}\text { Improved organizational culture by empowering and involving employees led to improved } \\
\text { knowledge sharing and decision making at all levels of DComp by developing participa- } \\
\text { tion-based routines through balanced scorecards and liP. }\end{array}$ \\
\hline
\end{tabular}

IiP helped in developing and implementing training and development routines (Figures 2 and 3 ) to assimilate the new knowledge acquired by teams and individuals. It also helped retain staff and establish recognition and reward schemes, such as social integration mechanisms (Figure 1), which in turn strengthened the assimilation process.

Human resources. Recruitment processes and procedures were developed to enhance absorptive capacity by employing the most appropriate people and adding to the firm's core competencies (Jones, 2006). Over the two-year period of the KTP programme, recruitment was initially difficult. This was followed by an improved situation due to the construction sector moving into recession. In DComp, internal recruitment took place through promotions and transfers. Internal recruitment tends to be for office-based workers: that is, administrative and managerial roles, providing motivation for staff. External recruitment was improved by more effective targeting of individuals, bringing new skills, ideas and experiences to the company (Easterby-Smith et al, 2008), thereby enhancing both the acquisition and assimilation of knowledge within DComp.
Cross-functional communication. Communication was encouraged among departments within DComp to increase social integration mechanisms and to lower the barriers to assimilating newly acquired knowledge. This approach included the development of boundaryspanning skills for leaders of the cross-functional teams designing the new and improved routines. IiP encouraged people's involvement and empowerment, with more employees (albeit a limited number) playing a role in decision making by using devolved balanced scorecards.

Organization structure. Through the KTP project, both formal and informal networks were established to encourage the assimilation of knowledge throughout the company and to overcome the limitations of the existing hierarchical organizational structure. Monthly team meetings involving the key change agents (Jones, 2006) and management meetings were established, encouraging employees to contribute to both operational and strategic issues (Daghfous, 2004).

In summary, the development of PACAP (Figure 1) within DComp led to the development of processes, procedures and routines to operationalize and improve 
dynamic capability, which was enabled by using adapted learning-based processes from the balanced scorecard and IiP, as shown in Figures 2 and 3. The challenge at this stage of the KTP programme was to convert PACAP into RACAP (RQ3) by improving the transformation and exploitation of the more effectively acquired and assimilated knowledge (Figure 1).

\section{Transformation}

Individual absorptive capacity. Individual absorptive capacity impacts on the firm's capability to develop and refine routines that allow for the combining of existing knowledge with newly acquired and assimilated knowledge to increase competitiveness (Zahra and George, 2002). Hence, multifunctional teams were used within the organization to communicate effectively, create a shared ideology and create formalized procedures and policies that were client-focused for improving communication and knowledge sharing (Linsu, 2004).

Management meetings and team meetings were established to improve communication and to set up formalized procedures using the operational loops shown in Figures 2 and 3.

Level of education. The relatively high levels of education within the firm helped in combining existing knowledge and skills with newly acquired knowledge (Todorova and Durisin, 2007). DComp has employees with varying levels of education, from skilled tradespeople to those with academic qualifications. This investment in training and development enabled individuals and teams to transform newly acquired and assimilated knowledge to meet the strategic goals of the organization. The high level of transformed knowledge (for example, in the incorporation of new design practices) within the company led to improved competitiveness in the new construction market, as originally suggested by Egan (1998) and the Rethinking Construction initiative.

Human resources. DComp's implementation of the Investors in People standard helped to establish routines to motivate continuous learning within the company by focusing on developing and training staff within a culture of continuous improvement, as incorporated within the tenets of the balanced scorecard and IiP, in which dynamic capability is continually increased (Figures 2 and 3). The new and modified routines were supported by a comprehensive training and development plan across all areas and levels of the company.

In the UK, it has been increasingly difficult to recruit graduates in the construction sector, due to competition from more attractive industries, poor public image and recruitment policies (Millar, 2005). The industry is attempting to close this skills gap, positioning itself as a career choice for young people by offering apprenticeships and construction-based university degrees. DComp now contacts universities directly for new recruits, and also takes on a number of apprentices and placement students each year to enable it to keep abreast of new technologies, techniques and materials, therefore increasing the potential to leverage and develop routines to increase dynamic capability and hence competitiveness (Zahra and George, 2002).

Internal communication. Fosfuri and Tribo (2008) suggest that efficient internal communication enhances social integration mechanisms, which improve information sharing and efficiency in the transformation of acquired and assimilated knowledge. Thanks to the KTP project, communication has improved through management and team meetings and the quarterly LMC meetings. Moreover, key agents such as subunit leaders have formed professional linkages to their peers outside the company in a 'community of practice' format. These meetings and networks helped to identify core competencies and established structured approaches to link procedures so as to increase the overall capability of the organization. Communication issues at internal organizational boundaries (lateral and vertical) were alleviated by designing and implementing cross-functional routines based on Easterby-Smith et al's (2008) pragmatic (shared routines) boundary classification.

Organizational structure and culture. The application of Investors in People encouraged all employees to become involved and empowered within a series of new organizational routines through using developed balanced scorecards and Kaizen techniques (Colenso, 2002). According to Daghfous (2004, p 24), 'when employees are empowered, a knowledge-sharing culture is encouraged'. This ultimately led to increased innovation in terms of new or modified products and services within DComp.

\section{Exploitation}

The exploitation dimension of ACAP inquires into the firm's application or use of transformed knowledge to achieve the organization's objectives (Lane and Lubatkin, 1998). The key influencing factors are similar to those of the transformation stage (Zahra and George, 2002).

To probe the development of the exploitation of ACAP within DComp, and to contribute further to RQ3, a key cross-functional business process, which interfaced directly with the external market, and which involved all four dimensions of ACAP, was considered 
as an example of improved dynamic capability within the company - namely the tendering process (that is, to gain access to the 'select lists' by demonstrating organizational capability). The KTP associate investigated both the process of environmental scanning or searching for new tenders, and the preparation of tender documents.

Construction companies must seek out jobs that are advertised in local newspapers, construction journals and linked Websites. These are known as 'select list' advertisements. Applying for a job involves either completing a capability-based questionnaire or sending out an information pack containing the information requested. All companies, regardless of status, must follow the same procedure. There is no standard reply, as applications can differ significantly for each contract. A great deal of care and attention must be spent on each application, as they are aimed at communicating to the client that DComp is the most appropriate company with sufficient capability to meet the client's current and anticipated needs efficiently and economically. The tender document must give the client confidence in the organization's capability to fulfil his or her needs (Preece et al, 2003). DComp introduced an element of passive marketing by ensuring that it was listed on all public sector approved contractors lists (for example, Constructionline and health trusts) and by emphasizing its newly developed absorptive capacity, interpreted in terms of approved or select list language. Client groups (or gatekeepers; see Zahra and George, 2002), such as government bodies, public services and large corporations, have lists of approved contractors, as well as preferred and priority contractors. DComp used its absorptive capacity KTP programme to address the criteria on these lists.

Exploitation-based targets were set and measured each month using the balanced scorecard at a corporate level and at team levels (based on specific skill groupings: for example, surveying). The resulting quality of the job applications has improved and the value of the applications has also increased. Moreover, cycle time for this process has been reduced by $25 \%$ across all bid levels. The value of the contracts applied for has increased by approximately $£ 1$ million, and the number of applications made has reduced by $25 \%$, reflecting a capability-targeted approach, as suggested by Briscoe and Dainty (2005), over the two-year period of the KTP programme. The number of successful applications has risen by an average of $30 \%$.

At a corporate level, the absorptive capacity-based KTP project, with new and improved processes, procedures and routines across all four dimensions of ACAP, helped make a substantial improvement to the competitive position of DComp Contracts Ltd, with an increase in turnover from $£ 5.7$ million in 2006 to a predicted $£ 10$ million in 2008, based on the last management accounts.

The KTP project has led to the introduction of more efficient management procedures, a new measurement system with tangible data, the establishment of new complaints and quality procedures, recognition of the need for more control over finances and the introduction of job costing procedures, appraisal procedures and new invoice systems. These activities that are associated with the changes in the organization have ultimately aggregated to improve the absorptive capacity of DComp and its exploitation potential.

The Office for National Statistics shows that there was a substantial drop in the value of construction sector output over the last 12 months. Orders in the 12 months to November 2008 fell 14\% compared with the previous 12 months. Performance output within DComp has increased over the same period. The authors recognize that, ultimately, long-term performance data will be needed to show sustainable positive trends or otherwise; however, the initial results are encouraging and reflect a movement from PACAP to RACAP (RQ3) consistent with the aim of the KTP programme.

\section{Conclusions}

It is concluded that operationalizing absorptive capacity requires interventions at individual, group and firm levels and that tools and techniques such as the balanced scorecard (Assiri et al, 2006) and Investors in People (Taylor and McAdam, 2003) and their associated learning processes can be adapted to ensure that changed or new routines contribute effectively to all the dimensions of ACAP. Routines such as those associated with IiP, ISO, the balanced scorecard, KTP, recruitment, training and Kaizen techniques are the processes or routines that support/stimulate the practices necessary to identify potential and to realize PACAP.

It was found that these routines needed to have 'learning-to-learn' loops (Jones, 2006; Figures 2 and 3), to ensure that they were continuously driven by changing market and organizational requirements, thus also ensuring they were both strategic and operational (Lin et al, 2002; Todorova and Durisin, 2007) and involved with the acquisition, assimilation, transformation and exploitation of knowledge to increase capability and competitiveness.

The influencing factors developed by Zahra and George (2002) for each of the ACAP dimensions helped in contextualizing how the SME could develop improved approaches in all of these areas. This contextualization and disaggregation of ACAP enabled meaningful and specific improvements to be made and targeted, as shown in Tables 1-3. This approach, 
coupled with the operationalization routines (Figures 2 and 3) enabled the SME to move from a theoretical understanding of ACAP at a macro level to using the construct to develop specific improvements at individual, group and firm levels, which Jones (2006) and Todorova and Durisin (2007) have identified as an area for development.

The application and development of absorptive capacity within the SME also demonstrated the link between PACAP and RACAP, as found by Zahra and George (2002). The longitudinal nature of the research (two years) showed that capability building in terms of acquisition and assimilation ultimately led to transformed routines and improved competencies, which resulted in increased organizational capability and competitiveness (Lane et al, 2006) in terms of inclusions on select lists and successful bids for DComp.

Consistent with Jones (2006) and Easterby-Smith et al (2008), it is suggested that further studies of organizational applications of ACAP should be developed using longitudinal and qualitative data, especially in SMEs, where rapid responses to market changes are essential to ensure sustained competitiveness.

\section{References}

Assiri, A., Zairi, M., and Riyad, E. (2006), 'How to profit from the balanced scorecard: an implementation roadmap', Industrial Management and Data Systems, Vol 106, No 7, pp 937-953.

Briscoe, G., and Dainty, A. (2005), 'Construction supply chain integration: an elusive goal', Supply Chain Management: An International Journal, Vol 10, No 4, pp 319-326.

Burnes, B., and Coram, R. (1999), 'Barriers to partnerships in the public sector: the case of the UK construction industry', Supply Chain Management: An International Journal, Vol 4, No 1, pp 43-53.

Carlile, P. R. (2002), 'A pragmatic view of knowledge and boundaries: boundary objects in new product development', Organization Science, Vol 13, No 4, pp 442-455.

Cheng, E., and Li, H. (2004), 'A learning culture for strategic partnering in construction', Construction Innovation, Vol 4, pp 53-65.

Cohen, W. M., and Levinthal, D. A. (1990), 'Absorptive capacity: a new perspective on learning and innovation', Administrative Science Quarterly, Vol 35, No 1, pp 128-152.

Colenso, M. (2002), 'Kaizen strategies for improving team performance: how to accelerate team development and enhance team productivity/contributions by associates of the Europe Japan Centre', Measuring Business Excellence, Vol 6, No 1, pp 60-70.

Daghfous, A. (2004), 'Absorptive capacity and the implementation of knowledge-intensive best practices', SAM Advanced Management Journal, Vol 69, No 2, pp 21-27.

Davenport, T. H., and Prusak, L. (1998), Working Knowledge: How Organisations Manage What They Know, Harvard Business School Press, Boston, MA.

Easterby-Smith, M., et al (2008), 'Absorptive capacity: a process perspective', Management Learning, Vol 39, No 5, pp 483501.

Egan, J. (1998), Rethinking Construction, Department of the Environment, Transport and the Regions, London.

Fosfuri, A., and Tribo, J. (2008), 'Exploring the antecedents of potential Absorptive Capacity and its impact on innovation performance', Omega, Vol 36, No 2, pp 173-187.
Freeman, C., and Soete, L. (1997), The Economics of Industrial Innovation, Pinter, London.

Hari, S., Egbu, C., and Kumar, B. (2005), 'A knowledge capture awareness tool: an empirical study on small and medium enterprises in the construction industry', Engineering, Construction and Architectural Management, Vol 12, No 6, pp 533-543.

Hussey, J., and Hussey, R. (1997), Business Research: A Practical Guide for Undergraduate and Postgraduate Students, Macmillan Business, Basingstoke.

Jones, O. (2006), 'Developing absorptive capacity in mature organisations: the change agents role', Management Learning, Vol 37, No 3, pp 355-376.

Jones, O., and Craven, M. (2001), 'Expanding capabilities in a mature manufacturing firm: absorptive capacity and the TCS', International Small Business Journal, Vol 19, No 3, pp 39-55.

Kaplan, R., and Norton, D. (1996), The Balanced Scorecard: Translating Strategy Into Action, Harvard Business School Publishing Corporation, NY.

Kaplan, R., and Norton, D. (2001), The Strategy-Focused Organisation: How Balanced Scorecard Companies Thrive in the New Business Environment, Harvard Business School Publishing Corporation, NY.

Khalfin, M., McDermott, P., and Swan, W. (2007), 'Building trust in construction projects', Supply Chain Management: An International Journal, Vol 12, No 6, pp 385-391.

Lane, P., Koka, B., and Pathak, S. (2006), 'The reification of Absorptive Capacity: a critical review and rejuvenation of the construct', Academy of Management Review, Vol 31, No 4, pp 833-863.

Lane, P., and Lubatkin, M. (1998), 'Relative absorptive capacity and interorganisational learning', Strategic Management Journal, Vol 19, No 5, pp 461-478.

Leonard-Barton, D. (2002), 'Core capabilities and core rigidities: a paradox in managing new product development', Strategic Management Journal, Vol 13, pp 111-137.

Lin, C., Tan, B., and Chang, S. (2002), 'The critical factors for technology Absorptive Capacity', Industrial Management and Data Systems, Vol 102, No 6, pp 300-308.

Linsu, K. (2004), 'Crisis construction and organisational learning: capability building in catching up at Hyundai Motor', Organisation Science, Vol 9, No 4, pp 506-521.

Loosemore, M., Dainty, A., and Lindard, H. (2003), Human Resource Management in Construction Projects: Strategic and Operational Approaches, Spon Press, London.

Mathews, J., et al (2000), 'Quality relationships: partnering in the construction supply chain', International Journal of Quality and Reliability Management, Vol 17, No 5, pp 493-506.

Millar, R. (2005), 'Construction jobs fall 70\% in Northern Ireland', Website: http://www.contractjournal.com.

Preece, C., Moodley, K., and Smith, P. (2003), Construction Business Development: Meeting New Challenges, Seeking Opportunity, Butterworth-Heinemann, London.

Reason, P., and Bradbury, H. (2001), Handbook of Action Research, Sage, London.

Remenyi, D., et al (1999), Research in Business and Management, Sage, London.

Riley, M., and Brown, D. (2001), 'Case study of the application of BPR in an SME contractor', Knowledge and Process Management, Vol 8, No 1, pp 17-28.

Saunders, M., Lewis, P., and Thornhill, A. (2007), Research Methods for Business Students, 4 ed, Prentice Hall, Upper Saddle River, NJ.

Simon, A., Sohal, A., and Brown, A. (1996), 'Generative and case study research in quality management, Part 1: Theoretical considerations', International Journal of Quality and Reliability Management, Vol 13, No 2, pp 75-87.

Taylor, A. (2008), 'Decline in job vacancies fastest for seven years', Financial Times, 3 September, p 3.

Taylor, J., and McAdam, R. (2003), 'A longitudinal study of business improvement models: cross purposes or congruity?' Managing Service Quality, Vol 13, No 5, pp 382-398. 
Absorptive capacity in a construction SME

Teece, D. J., Pisano, G., and Shuen, A. (1997), 'Dynamic capabilities and strategic management', Strategic Management Journal, Vol 18, pp 509-533.

Todorova, G., and Durisin, B. (2007), 'Absorptive capacity: valuing a reconceptualisation', Academy of Management Review, Vol 32, No 3, pp 774-786.

Veugelers, R. (1997), 'Internal R and D expenditures and external technology sourcing', Research Policy, Vol 26, No 3, pp 303-315.

Yin, R. K. (2003), Case Study Research: Design and Methods, 3 ed, Sage, London.

Zahra, S., and George, G. (2002), 'Absorptive capacity: a review, reconceptualisation, and extension', Academy of Management Review, Vol 27, № 2, pp 185-203. 